NBER WORKING PAPER SERIES

\title{
CAPITAL ACCOUNT LIBERALIZATION AS A SIGNAL
}

\author{
Leonardo Bartolini \\ Allan Drazen
}

Working Paper 5725

\section{NATIONAL BUREAU OF ECONOMIC RESEARCH 1050 Massachusetts Avenue \\ Cambridge, MA 02138 \\ August 1996}

We thank M. Annunziata, M. Baxter, G. Calvo, G.M. Milesi-Ferretti, A. Razin, N. Roubini, A. Tornell, two referees, and participants in seminars at Boston College, the European University Institute, Georgetown, Harvard, Hebrew University of Jerusalem, IMF, Maryland, MIT, NBER, NYU, NY Fed, Penn State, UCLA, Wisconsin, and the World Bank for comments and suggestions, and N. Gunaratne and A. Peterson for technical support. This paper is part of NBER's research program in International Finance and Macroeconomics and NBER's project on International Capital Flows and was presented at the NBER conference, "Universities Research Conference on the Determination of Exchange Rates." We are grateful to the Center for International Political Economy for the support of this project. Errors and omissions are our responsibility. Any opinions expressed are those of the authors and not those of the Federal Reserve System or the National Bureau of Economic Research.

(C) 1996 by Leonardo Bartolini and Allan Drazen. All rights reserved. Short sections of text, not to exceed two paragraphs, may be quoted without explicit permission provided that full credit, including $@$ notice, is given to the source. 


\title{
CAPITAL ACCOUNT LIBERALIZATION AS A SIGNAL
}

\begin{abstract}
We present a model in which a government's current capital controls policy signals future policies. Controls on capital outflows evolve in response to news on technology, conditional on government attitudes towards taxation of capital. When there is uncertainty over government types, a policy of liberal capital outflows sends a favorable signal that may trigger a capital inflow. This prediction is consistent with the experience of several countries that have liberalized their capital account.
\end{abstract}

Leonardo Bartolini

Federal Reserve Bank of New York

Federal Reserve P.O. Station

New York, NY 10045

\author{
Allan Drazen \\ Center for International Economics \\ 4118 Tydings Hall \\ University of Maryland \\ College Park, MD 20742 \\ and NBER \\ DRAZEN@ECON.UMD.EDU
}


Controls on international capital flows are a common form of financial regulation. Changes in the extent of these controls are also common. Of 182 countries surveyed by the IMF in 1995, 129 were classified as restricting international capital transactions. At least 50 of them had significantly altered these regulations in the previous 12 months.

Despite the widespread use of capital controls and the frequency with which such restrictions are modified, little work has been done to model the impact of changes in these regulations on capital flows. Perhaps this deficiency reflects the view that the effect of lifting or imposing controls is clear from basic economic theory. Consider, for example, the removal of restrictions on capital outflows. If controls are binding when the liberalization is implemented (so that offshore returns exceed onshore returns), a liberalization should lead to a capital outflow, as funds flow to where returns are highest,' while removal of nonbinding controls should have no effect.

Actual experience with lifting controls, however, tells a different story. Many countries that have removed controls on outflows have experienced rapid and massive inflows of capital. $^{2}$ A popular explanation, motivated by the work of Dooley and Isard (1980), was formalized by Labán and Larraín (1993). Controls that prevent investors from withdrawing capital from a country act like investment irreversibility. Their removal makes investors more willing to invest in a country, as it easier to get their capital out in the future.

However, the link between capital controls and investment flexibility, though essential to any model of capital controls, provides a partial explanation of capital inflows. This explanation depends crucially on expected persistence of current policies, but, unlike technological constraints, policies may change. In fact, governments that succeed in attracting 
foreign investment have a strong incentive to lock the door once the fattened calves have come inside. To make sense of the flexibility argument and motivate the persistence of policies affecting capital mobility, one needs a model that captures the interaction between optimizing, forward-looking investors and governments.

Our approach to modeling capital controls and explaining the observed inflows following the adoption of a regime of liberal outflows views capital controls as potential signals of future government behavior. Specifically, we suggest that besides providing greater flexibility for current allocation of capital, a regime of free capital mobility may signal that imposition of controls is less likely to occur in the future and, more generally, that future policies are likely to be more favorable to investment. Our argument rests on the belief that investors have imperfect information on governments' intentions and constraints, and may therefore use the observation of current policies toward investment to infer the course of future policies. This gives governments an incentive to allow free capital mobility so as to provide a favorable signal on future investment policies. If the signal is successful, capital flows in.

A signaling model must make this motive consistent with the ultimate purpose of capital controls, which is often to broaden the domestic tax base. Countries with poorly developed tax systems often rely on revenues from financial repression, enforcing a differential between onshore and offshore returns to capital by regulations aimed at "trapping" capital onshore. In our model, it is precisely those governments that depend most on such a tax base that impose controls, even though such controls may lead to a lower expected tax base. 
To make the argument convincing, we must show that governments use capital controls as an equilibrium response to information they receive: the choice of an open capital account signals good news about the future, and vice versa. However, if adoption of a regime of free capital mobility is expected to lead to a capital inflow, why would a government that expects bad times not attempt to take advantage of this? (Formally, the question is: Why does a separating equilibrium prevail, rather than a pooling equilibrium in which all governments choose not to impose controls.) To answer this question, we show that some governments choose to impose capital controls, even though they know this is interpreted as an unfavorable signal.

The argument behind this result is simple. Consider a government that raises revenue from several sources, including capital taxation, to finance the provision of public goods. Suppose that revenues (and hence expenditures) have a stochastic component and that government welfare is highly concave in the level of expenditure, so that low expenditure implies very low welfare. A government that anticipates low revenues from other sources is especially sensitive to the possibility of low capital tax collection. It will then impose controls to self-insure against bad states of nature (when capital would flow out), thereby assuring a minimum level of revenues in all states of nature. It will impose controls, even though, by doing so, it may forgo higher revenues on average across all states.

Our approach has both strengths and limitations. First, in contrast to most previous studies, we model capital controls as a dynamic component of governments' problem rather than as exogenous constraints applying over the whole horizon. Second, unlike the standard symmetric modeling of controls on inflows and outflows, we recognize that real-world 
controls are typically asymmetric: stricter either on inflows or--more frequently--on outflows. Greater realism in these respects comes at the cost of simplification elsewhere. For instance, we do not distinguish between restrictions on short-term (or portfolio) and those on long-term (or FDI) flows, nor between restrictions on residents and nonresidents, although one may imagine situations where liberalizing residents' portfolio activity alone may send a favorable signal, thereby indirectly promoting other inflows. Also, we focus solely on policies affecting capital mobility, although we are aware that capital account liberalization is often only one element of broader reform programs. However, by focusing on a single motive for inflows, we can make the clearest case for the signaling role of policies affecting capital mobility. Our model suggests that imperfect information about a government's intentions may provide an incentive to use free capital mobility to enhance the credibility of a broader reform program. It is to a reformist government's advantage to show an early commitment to an open capital account, by exposing itself to risks that less committed governments cannot afford.

The paper is structured as follows. The next section reviews the liberalization experience of a number of countries, pointing to stylized facts that are consistent with our model of capital controls but may be more difficult to explain by alternative models. The model is described in Section 2 and solved in Section 3. Section 4 discusses the results, and Section 5 concludes.

\section{Capital controls: Some stylized facts and liberalizations episodes}

We begin with a few stylized facts. First, capital controls are much more common 
among developing countries than among industrial countries. At the beginning of 1995, for instance, capital controls were used by 126 of 158 developing countries, against only 3 of 24 OECD countries (Greece, Norway, and Turkey).

Second, capital controls are predominantly aimed at restricting capital outflows. These controls take a variety of forms, including quantitative restrictions and outright prohibition of outflows, requirements to surrender a portion of the outflow to a low interest rate account, and dual exchange rates. Though these regulations look different, in practice all aim at stemming outflows by making their cost prohibitive.

Third, capital controls appear to play two main roles, either in support of governments' attempt to broaden the tax base for a capital levy, inflation tax, and various forms of "financial repression", or in support of fixed or managed exchange rate policies.

Finally, liberalizations of capital outflows are often accompanied by a sharp increase in net capital inflows, as the experience of some countries that have recently liberalized their capital accounts illustrates. (See Figure 1 for summary data.) The four episodes we review are those of Italy, New Zealand, Uruguay, and Spain.

Italy began to dismantle its system of controls on capital outflows in November 1984 . The compulsory zero-interest deposit on portfolio investment abroad was reduced for residents and abolished for mutual funds. The surrender requirement was further reduced in 1985 and 1986 and abolished in 1987, and the crediting of banknotes to capital accounts was liberalized in August 1986. Though the liberalization was completed only in May 1990, its main steps occurred in 1986 and 1987, after which remaining restrictions ceased to be binding (see Bartolini and Bodnar, 1992 and Giavazzi and Giovannini, 1989, for analysis of this episode). 
Large inflows were recorded from 1987, and private investors were primarily responsible for them. ${ }^{3}$

In November 1984, New Zealand abolished the exchange and capital controls that had been in place since 1938, as part of a broad policy of financial liberalization. In contrast with the policies followed by Italy and Spain during the 1980s (where the liberalization was part of a policy of greater exchange rate fixity), New Zealand floated its exchange rate soon after the liberalization. The capital liberaliza-tion was rapid and focused on the lifting of restrictions on outflows, including the surrender of foreign exchange receipts and limits on holdings of foreign securities and on raising of domestic funds by foreign companies. Interestingly, although the financial market was liberalized in June and July 1984, capital inflows did not surge until year-end, when the capital account was liberalized. In fact, the net inflow recorded in 1984 appears to have occurred wholly in the last two months of the year. Capital inflows surged in 1985,1986 , and 1987 , with private investors playing, once again, the principal role. ${ }^{4}$

After nearly two decades of inward-looking policies and financial repression, Uruguay began to implement radical reforms in the mid-1970s, including trade and financial deregulation, and--foremost--liberalization of capital flows. ${ }^{5}$ The liberalization of capital flows proceeded at the fastest pace and before other major policy changes: in September 1974, exchange rate controls (primarily on outflows) were eliminated and residents were permitted to hold dollar accounts with domestic banks for the first time, and repatriation of capital and profits connected with FDI was permitted. Large capital inflows were recorded in the four years beginning in 1974. Private investors (mainly from Argentina and the U.S.) 
played an essential role also in this episode, a feature we document in Figure 1 by netting official net loans from net capital inflows (assuming negligible official acquisitions of equity and real estate, and negligible foreign investment of the domestic public sector).

After its entry into the EC in 1986, Spain liberalized capital flows, as part of a broader plan of fiscal and monetary reform. Both capital outflows and inflows were liberalized. ${ }^{6}$ Evidence from offshore-onshore interest differentials, however, shows that prior to the liberalization, controls on outflows were more stringent than on inflows (Viñals, 1990). In fact, after the liberalization, the positive offshore-onshore interest differential disappeared and then turned negative when temporary controls on inflows were introduced to stem the rapid inflow recorded in 1987. Excluding measures affecting FDI, the main steps in the liberalization included the lifting of restrictions on residents' direct and portfolio investment abroad, on forward exchange operations, and on real estate investment abroad. Although the liberalization was completed only in 1992, net capital inflows (net of FDI) surged immediately after the initial steps of 1986, and continued unabated until the ERM crisis of 1992. Once again, private investors played a primary role in the inflow, as documented in Figure 1, which nets changes in the stock of official loans from total capital flows (excluding FDI; see also Schadler et al., 1993, for a discussion of this episode).

These episodes can be summarized as follows: the liberalizations focussed on removing restrictions on capital outflows; they represented early ingredients of broad reforms that included the lifting of various elements of financial repression; and they were accompanied by a surge in net capital inflows. In the next section we present a model capturing several of these stylized facts. 


\section{The model}

Consistent with the arguments outlined in the introduction, in our model decisions on capital controls are driven by governments' desire to increase the stock of domestic capital. Our main results require government behavior to display two basic features: first, government utility (net of the cost incurred when imposing capital controls) should increase in the stock of domestic capital; second, the willingness to incur the costs of controls should differ across governments in a way (at least, partially) unknown to investors.

Many of the motives for (and costs of) capital controls suggested in the literature could meet these requirements and fit into our framework. For instance, utility from domestic capital could reflect a government's interest in maximizing domestic output, tax base, or official reserves. ${ }^{7}$ Costs of controls could reflect concern with distortionary effects on capital allocation, penalties enforced by other countries for engaging in beggar-thy-neighbor policies (penalties that may include limits on trade credit, exclusion from participation in coordinated policies, etc.), or other economic and political factors that affect the importance governments assign to capital mobility. ${ }^{8}$ Governments may also be concerned with the effects of controls on residents' ability to smooth consumption through capital flows, although the practical relevance of this motive has been questioned. ${ }^{9}$ A different and important argument concerns the use of controls to insulate a country from external shocks. The difficulties associated with the recent large inflows and subsequent outflows in Latin America, which culminated in the Mexican crisis of late 1994, underscore the importance of this motive, whose analysis would require, however, a substantially different model. Although analytical clarity dictates our focus on a single motive for controls, we later discuss how our results may extend beyond 
our specific model.

To capture these considerations formally, we present the simplest model we could design to yield our main results.

We consider a two-period model of a small open economy where a single nonstorable, homogeneous good $Y_{t}$ is produced at time $t$ with onshore capital $K_{t}$, using a concave technology $Y_{t}=\mu_{t} K_{l}^{\beta}$, where $\mu_{t}$ is a stochastic productivity shock and $0<\beta<1$. The stock of onshore capital $K_{t}$ reflects the decisions of competitive, risk-neutral investors. In each period, investors allocate capital either offshore (at a fixed return $r$ ) or onshore, to maximize total expected returns, discounted by the factor $\rho=1 /(1+r)$, over the residual horizon. ${ }^{10}$ (For simplicity we also set the government's discount factor at $\rho$.) Absent adjustment costs, the return to physical and financial capital is equalized and we make no distinction between the two. For simplicity, and given the ambiguous evidence in support of capital flows for consumption-smoothing purposes (see Footnote 9), we ignore this motive in our analysis. (Formally, this treatment would follow from the assumption of households' linear utility; see Frenkel and Razin, 1987, for a complete discussion.) We thus focus on investors' capital allocation decisions in response to technology shocks, given endogenous constraints on capital mobility. ${ }^{11}$

The government taxes capital wealth (for simplicity, only at the end of period two), at a predetermined rate $\tau$, collecting revenues $\tau K_{2}{ }^{12}$ Governments differ by the value they attach to this revenue. This heterogeneity may reflect differences in preferences for expenditures, in willingness to tap revenues other than capital taxation, or in the importance assigned to free capital mobility, differences which cannot be signaled simply by 
announcement. We parameterize these differences by a variable $x \in(-\infty, \infty)$, and assume governments to have greater information on $x$ than investors. Although many factors may differentiate governments' willingness to use controls (especially their commitment to noninterventionist policies), for concreteness we treat $x$ simply as revenues (or obligations, when $x<0$ ) other than capital taxation, to which the government has access or is willing to use (or service) at the end of period two. At the end of period two, the government transforms the sum $\tau K_{2}+x$ into nonmarketed public goods and derives utility $W($.) from their supply. This function is increasing, continuous, concave, and satisfies the regularity conditions $\lim _{z \rightarrow-\infty} W(z)=-\infty, \lim _{z \rightarrow-\infty} W^{\prime}(z)=\infty$, and $\lim _{z \rightarrow \infty} W^{\prime}(z)=0 .^{13}$ Thus, government utility from onshore capital is increasing in $\tau K_{t}+x$ (so that a potentially larger captive tax base tempts governments to impose controls), but at a decreasing rate (so that a larger $x$ reduces the incentives to trap a given stock of capital). We model asymmetric information by assuming that governments are informed about $x$ at the beginning of period one, whereas investors learn this only at the beginning of period two. We refer to $x$ as a government's type; a higher $x$ identifies governments with greater outside resources or greater willingness to tap those resources. Investors have a prior cumulative probability distribution over types, $\mathrm{G}(x)$

We model the direct costs of controls very simply. (Naturally, "reputational" costs are an integral part of our story and are analyzed below.) Similarly to other models in the signaling literature, we interpret the cost of controls simply as the cost to the government of breaking a commitment to free capital mobility: ${ }^{14}$ whenever controls are in place, the government pays a cost $\xi>0$. This approach simplifies the exposition by making the cost of 
controls independent of whether or not controls turn out to bind ex post. ${ }^{15}$

The model's timing is summarized in Table 1 . The initial state is summarized by the initial capital stock, $K_{0}$, and $\mathrm{G}(x)$. At the beginning of each period, before observing current productivity, the government announces whether capital flows are free or restricted in period $t$. When controls are imposed, the end-of-period stock of domestic capital, $K_{t}$, is constrained to be at least as large as at the beginning of the period, that is, $K_{t} \geq K_{t-1}$, with $K_{0}>0 .{ }^{16}$ (We use a dummy variable $c_{t}$ to denote the period $t$ regime, letting $c_{t}=\mathrm{F}$ and $c_{t}=\mathrm{R}$ denote the cases of free and restricted mobility, respectively.) For economy of exposition, we shall often refer to the adoption of a regime of free capital mobility simply as a "liberalization" though, strictly speaking, this term should be reserved to describe a switch from a regime with capital controls to one without controls. In Section 4, we discuss when a "liberalization" in the strict sense may indeed emerge endogenously in our model.

After the government has announced the financial regime, nature reveals current-period productivity $\mu_{t}$, which may take the values $\{0, \mu\}$. We initially assume $\mu_{t}$ to be serially uncorrelated and write the probabilities of $\mu_{t}=0$ and $\mu_{t}=\mu$ as $1-\pi$ and $\pi$, respectively. We later discuss some implications of the more realistic assumption that $\mu_{t}$ is serially correlated. After $\mu_{t}$ has been revealed, investors choose $K_{t}$ (in accord with the announced regime) and profits (as well as taxes, in period two) are collected at the end of the period.

\section{Solution}

Solving the model backward from period two leads us to a unique Perfect Bayesian Equilibrium, a standard equilibrium concept in the signaling literature. (See, for example, 
Fudenberg and Tirole, 1991).

A. Period-two equilibrium. After observing $\mu_{2}$, investors compare the marginal return from investing offshore (inclusive of principal), $\rho(1+r)$, to that from investing onshore, $V_{2}=\rho\left(\mu_{2} \beta K_{2}^{\beta-1}+(1-\tau)\right)$ (inclusive of the scrap value of a unit of capital). With free capital mobility, profit maximization equalizes $\rho(1+r)$ and $V_{2}$, yielding the optimal level of onshore investment

$$
K_{2}^{*}\left(\mu_{2}\right) \equiv\left[\frac{\beta \mu_{2}}{r+\tau}\right]^{\frac{1}{(1-\beta)}} \text {, }
$$

which equals zero if $\mu_{2}=0$. If, instead, capital controls are in place in period two, investors may be unable to attain this solution, since the domestic stock of capital must satisfy the constraint $K_{2} \geq K_{1}$. Then,

$$
K_{2} \equiv \max \left\{K_{1}, K_{2}^{*}\left(\mu_{2}\right)\right\}
$$

Thus, depending on the inherited stock $K_{1}$, capital controls may or may not bind in period two in the high state $\mu_{t}=\mu$. However, controls certainly bind (and the corner solution $K_{2}=K_{1}$ prevails) in the low state $\mu_{t}=0$, if a positive $K_{1}$ is inherited from period one. This possibility, given investors' period-one uncertainty about the risk of controls in period two, plays a crucial role in the period-one equilibrium studied below.

At the beginning of period two, the government decides whether or not to impose controls, given the inherited stock $K_{1}$. The government's problem can be summarized by the function $\psi_{2}=\psi_{2}\left(K_{1}, x\right)$, which defines a type $x$ 's expected utility gain from imposing controls. Types for which $\psi_{2}>0$ impose controls in this period, while the remaining types allow free 
capital mobility (wit no loss of generality, indifferent types allow free mobility). $\psi_{2}$ is defined as

$$
\begin{aligned}
\psi_{2}\left(K_{1}, x\right) & \equiv \rho \mathrm{E}_{2}\left[W\left(\tau K_{2}+x\right) \mid K_{1}, c_{2}=\mathrm{R}\right]-\rho \xi-\rho \mathrm{E}_{2}\left[W\left(\tau K_{2}+x\right) \mid K_{1}, c_{2}=\mathrm{F}\right] \\
= & \rho\left[\pi\left[W\left(\tau K_{1}+x\right)-W\left(\tau K_{2}^{*}(\mu)+x\right)\right] \mathrm{I}^{\prime}+(1-\pi)\left[W\left(\tau K_{1}+x\right)-W(x)\right]-\xi\right],
\end{aligned}
$$

where the indicator function $\mathrm{I}^{\prime} \equiv \mathrm{I}\left(K_{1}>K_{2}{ }^{*}(\mu)\right)$ equals one when $K_{1}$ exceeds the optimal periodtwo stock in the high productivity state $\mu_{2}=\mu$, and zero otherwise.

Under the model's assumptions (in particular, the concavity of $W().), \psi_{2}=\psi_{2}\left(K_{1}, x\right)$ decreases monotonically in $x$ from $\infty$ to $-\rho \xi$. Hence, the period-two equilibrium features a low range of types (those for whom $\psi_{2}>0$ ), who impose capital controls in period two, and a higher range of types with sufficient outside resources that $\Psi_{2} \leq 0$, who allow free capital mobility. This property is intuitive: capital controls raise expected tax revenues in period two (the tax base is higher with binding controls and unchanged otherwise), thus raising a government's expected utility from public expenditure. The concavity of $W($.$) implies that$ this utility gain falls with $x$, though. For sufficiently large $x$, the gain from broadening the tax base is outweighed by the cost of controls. Also, $\psi_{2}$ rises with the inherited stock of capital $K_{1}$ : a higher $K_{1}$ provides a potentially larger captive tax base, and hence stronger temptation to impose controls. Based on these properties, we now study the equilibrium prevailing in period one.

B. Period one: signaling equilibrium. In period one, investors also compare the expected returns from onshore and offshore investment. In so doing, however, they must consider the probability that capital controls may be imposed in period two, a probability that reflects their 
current beliefs over government types, conditional on the policy chosen by the government at the beginning of period one.

To study this problem, denote the probability that controls may be imposed in period two after having been imposed in period one as $\gamma^{\mathrm{R}} \equiv \gamma^{\mathrm{R}}\left(K_{0}, K_{1}\right)=\operatorname{Pr}\left(c_{2}=\mathrm{R} \mid c_{1}=\mathrm{R}\right)$ and the probability that controls may be imposed in period two after not having been imposed in period one as $\gamma^{\mathrm{F}} \equiv \gamma^{\mathrm{F}}\left(K_{0}, K_{1}\right)=\operatorname{Pr}\left(c_{2}=\mathrm{R} \mid c_{1}=\mathrm{F}\right)$. (These probabilities depend on both $K_{0}$ and $K_{1}$, as these affect the incentives of governments to impose controls in period one and two, respectively.)

Next, the marginal return from investing offshore in period one is $\rho r+\rho^{2}(1+r)$ : in equilibrium, by going offshore in period one, investors earn the risk-free rate in both periods. The expected marginal return from investing onshore in period one, $V_{1}$, is

$$
\begin{aligned}
& V_{1}\left(K_{1}, \mu_{1}, c_{1}, K_{0}\right)=\rho \beta K_{1}^{\beta-1} \mu_{1}+\rho^{2}(1+r)\left[\operatorname{Pr}\left(c_{2}=\mathrm{F}\right)+\operatorname{Pr}\left(c_{2}=\mathrm{R}, \text { not binding }\right)\right] \\
& +\rho^{2}\left[1-\tau+\beta K_{1}^{\beta-1} \mathrm{E}_{1}\left[\mu_{2} \mid c_{2}=\mathrm{R} \text {, binding }\right]\right] \operatorname{Pr}\left(c_{2}=\mathrm{R}, \text { binding }\right) \\
& \quad=\rho \beta K_{1}^{\beta-1} \mu_{1}+\rho^{2}(1+r)-\rho^{2} \gamma^{c_{1}}\left[(r+\tau)\left(1-\pi\left(1-\mathrm{I}^{\prime}\right)\right)-\pi \mu \beta K_{1}^{\beta-1} \mathrm{I}^{\prime}\right],
\end{aligned}
$$

where $\mathrm{I}^{\prime}=1$ if $K_{1}>K_{2}^{*}(\mu)$ and zero otherwise, and $\gamma^{c_{1}}$ stands for either $\gamma^{\mathrm{F}}$ or $\gamma^{\mathrm{R}}$, depending on whether $c_{1}=\mathrm{F}$ or $c_{1}=\mathrm{R}$.

The term $-\rho^{2} \gamma^{c_{1}}\left[(r+\tau)\left(1-\pi\left(1-I^{\prime}\right)\right)-\pi \mu \beta K_{1}^{\beta-1} I^{\prime}\right]$ in the last line of (4) captures the "political risk" faced when investing in a country subject to potential capital controls. If the probability of controls in period two, $\gamma^{c_{1}}$, is zero, then the period-one marginal product of onshore capital, $\beta K_{1}^{\beta-1} \mu_{1}$, equals the offshore rate $r$, as both onshore and offshore capital yield $\rho r+\rho^{2}(1+r)$. In contrast, when the probability of controls in period two is positive, 
then the stock $K_{1}$ falls in period one, thus raising the period-one onshore return flow (the marginal product of capital) above the offshore rate.

The probabilities $\gamma^{\mathrm{R}}$ and $\gamma^{\mathrm{F}}$ are obtained by Bayes' rule from the prior probability that $c_{2}=\mathrm{R}$, conditional on the policy observed in period one. To clarify the updating process, denote by $R_{1}$ the set of types imposing controls in period one, and by $R_{2}$ the set of types imposing controls in period two. These sets are defined by $\mathrm{R}_{1} \equiv \mathrm{R}_{1}\left(K_{0}\right) \equiv\left\{x: \psi_{1}\left(K_{0}, x\right)>0\right\}$ and $\mathrm{R}_{2} \equiv \mathrm{R}_{2}\left(K_{1}\right) \equiv\left\{x: \psi_{2}\left(K_{1}, x\right)>0\right\}$, where $\psi_{2}$ is defined in (3), and $\psi_{1}$ is similarly defined in (7) below. Also, denote by $\mathrm{G}\left(\mathrm{R}_{1}\right) \equiv \int_{\mathrm{R}_{1}} \mathrm{dG}(x)$ the prior probability of $c_{1}=\mathrm{R}$, by $\mathrm{G}\left(\mathrm{R}_{2}\right) \equiv \int_{\mathrm{R}_{2}} \mathrm{dG}(x)$ the prior probability of $c_{2}=\mathrm{R}$, and by $\mathrm{G}\left(\mathrm{R}_{1} \cap \mathrm{R}_{2}\right) \equiv \int_{\mathrm{R}_{1} \cap \mathrm{R}_{2}} \mathrm{dG}(x)$ their joint probability. Then, by Bayes' rule,

$$
\gamma^{\mathrm{R}} \equiv \operatorname{Pr}\left(c_{2}=\mathrm{R} \mid c_{1}=\mathrm{R}\right)=\operatorname{Pr}\left(c_{2}=\mathrm{R}\right) \cdot \frac{\operatorname{Pr}\left(c_{1}=\mathrm{R} \mid c_{2}=\mathrm{R}\right)}{\operatorname{Pr}\left(c_{1}=\mathrm{R}\right)}=\mathrm{G}\left(\mathrm{R}_{2}\right) \cdot \frac{\mathrm{G}\left(\mathrm{R}_{1} \cap \mathrm{R}_{2}\right)}{\mathrm{G}\left(\mathrm{R}_{1}\right) \cdot \mathrm{G}\left(\mathrm{R}_{2}\right)}
$$

Equation (5) illustrates the effects of the persistence of government policies on the perceived probability of period-two controls. The update factor $\frac{G\left(R_{1} \cap R_{2}\right)}{G\left(R_{1}\right) \cdot G\left(R_{2}\right)}$ multiplies the prior $\mathrm{G}\left(\mathrm{R}_{2}\right)$ : should capital controls' decisions be independent across periods, then $G\left(R_{1} \cap R_{2}\right)=G\left(R_{1}\right) \cdot G\left(R_{2}\right)$ and the posterior probability of period-two controls, $\gamma^{R}$, would equal its prior, $G\left(R_{2}\right)$. When $G\left(R_{1} \cap R_{2}\right)>G\left(R_{1}\right) \cdot G\left(R_{2}\right)$, instead, then capital controls provide an unfavorable signal of future policies, as governments imposing controls in period one are also more likely to do so in period two. In this case, the posterior probability of period-two controls rises above its prior. The intuition behind the upgrade of $\gamma^{\mathrm{F}}$, is symmetrical.

Next, note that $V_{1}$ is a continuous and decreasing function of $K_{1}$, for both $c_{1}=\mathrm{F}$ and 
$c_{1}=\mathrm{R}$, going from infinity for $K_{1} \rightarrow 0$, to $-\rho^{2} \tau$ for $K_{1} \rightarrow \infty .{ }^{17}$ The unconstrained period-one profit-maximizing capital stock, $K_{1}^{*}=K_{1}^{*}\left(\mu_{1}, K_{0}, c_{1}\right)$, is then defined as the unique solution for $K_{1}$ of

$$
\rho r+\rho^{2}(1+r)=V_{1}\left(K_{1}, \mu_{1}, c_{1}, K_{0}\right)
$$

Finally, since the term in square brackets in (4) is positive (offshore returns exceed onshore returns with binding controls), then any rise in $\gamma^{c_{1}}$ reduces the return to $K_{1}$, and hence $K_{1}^{*}$ itself. This key link underlies our signaling equilibrium: when governments evaluate policy options at the beginning of period one, they know that actions leading to a higher perceived probability of controls in period two will induce a lower desired capital stock in period one.

We can now close the model by examining the problem faced by a government of type $x$ in period one. This problem is summarized by the function $\psi_{1}=\psi_{1}\left(K_{0}, x\right)$ that defines a type $x$ 's expected utility from imposing controls in this period one, as a function of the existing capital stock:

$$
\psi_{1}\left(K_{0}, x\right)=\rho^{2} \mathrm{E}_{1}\left[W\left(\tau K_{2}+x \mid c_{1}=\mathrm{R}\right)-W\left(\tau K_{2}+x \mid c_{1}=\mathrm{F}\right)\right]-\rho \xi-\rho^{2} \xi \mathrm{I}^{\prime \prime}
$$

where expectations are taken over realizations of $\mu_{1}$ and $\mu_{2}$, and the indicator function $\mathrm{I}^{\prime \prime} \equiv \mathrm{I}\left(c_{2}=\mathrm{R}\right)$ equals one when controls are in place in period two and zero otherwise.

The properties of $W($.$) assure that \lim _{x \rightarrow-\infty} \psi_{1}\left(K_{0}, x\right)=\infty$, and $\lim _{x \rightarrow \infty} \psi_{1}\left(K_{0}, x\right)=-\rho \xi$ for all $K_{0}>0$. Within these extreme values, the behavior of the (continuous) function $\psi_{1}$ determines government policies in period one, just as $\psi_{2}$ does for period two: types for 
which $\psi_{1}>0$ impose controls in period one, while types for which $\psi_{1} \leq 0$ do not. While the relative generality of our model does not allow us to characterize the solution for period one as simply as for period two,$^{18}$ we can nonetheless characterize government behavior in several important respects and study its implications for capital flows. Proposition 1 summarizes an important property: the adoption of free capital mobility in period one provides a favorable signal, by reducing the posterior probability of controls in period two:

Proposition 1. In equilibrium, $\gamma^{\mathrm{F}}\left(K_{0}, K_{1}^{*}\left(\mu, K_{0}, c_{1}=\mathrm{F}\right)\right)<\gamma^{\mathrm{R}}\left(K_{0}, K_{1}^{*}\left(\mu, K_{0}, c_{1}=\mathrm{R}\right)\right)$, for all $K_{0}>0$ and $\mu>0$ : the probability of controls in period two is higher conditional on capital controls than on free capital mobility in period one.

The intuition behind Proposition 1 (whose proof is in Appendix) is simple. Since capital control policies are positively correlated across periods, the observation of free mobility in period one provides a favorable signal of future policies (that is, it reduces the posterior probability of controls in period two). The formal argument behind this correlation is best made by contradiction, by assuming that policies are negatively (or not at all) correlated and noting that in this case low $x$ types would be more inclined to impose controls in period one than high $x$ types. Indeed, if the probability of period-two controls falls upon observing controls in period one, then imposing controls in period one would always raise the end-of-period capital $K_{1}$, and the eventual tax base $K_{2}$ : in bad states of nature (where capital controls trap capital above its desired level), and in good states (where the assumed favorable signal provided by capital controls increases the desired stock itself). In this case, however, lower $x$ types would be more inclined to impose controls (just as they do in period two), 
since the concavity of their utility function strengthens their taste for a broader tax base.

Hence, observing controls in period one would increase, rather than decrease (as assumed), the likelihood of controls in period two.

Based on Proposition 1 and on the solution to investors' problem, Section 4 further discusses the first period's equilibrium and its implications for capital flows.

\section{Properties of the equilibrium}

A. Who imposes controls? Our model embodies predictions on what type of governments and circumstances are likely to lead to capital controls. These predictions emerge clearly in period two, due to the simple solution available in this case: ceteris paribus, governments with fewer outside resources, $x$, or facing greater temptation to impose controls (in terms of a larger, potentially captive, capital tax base, $K_{1}$ ), are more likely to impose controls. Similar predictions emerge in period one, although the interaction between direct and indirect effects of $x$ and $K_{0}$ in the signaling equilibrium blurs the impact of small changes in these two variables. Nonetheless, the effects of $x$ and $K_{0}$ eventually dominate: free mobility prevails in period one as $x \rightarrow \infty$ or $K_{0} \rightarrow 0$, whereas controls prevail as $x \rightarrow-\infty$ or $K_{0} \rightarrow \infty$.

These predictions seem realistic. Although the parameter $x$ could capture any of many factors that affect capital account policies, the interpretation we emphasize--that $x$ represents revenues other than from capital taxation which the government may tap in the future--seems empirically appealing. Both casual evidence (showing more frequent use of capital controls in developing than in industrial countries--see Section 1), and evidence from panel studies (see, for instance, Alesina, Grilli, and Milesi-Ferretti, 1994), indicate that countries are more 
likely to impose capital controls when their expected revenues from financial repression are high relative to expected revenues from other sources (here represented by $x$ ). ${ }^{19}$ Thus, our model's implication that a larger $K_{0}$ should provide stronger temptation to impose controls, must be read in a relative sense: developing countries are more likely to use capital controls, not because their stock of taxable capital is high in absolute terms but because it is high relative to other revenue sources they can tap.

B. Capital flows. Several important properties of the model's equilibrium should be noted. First, as long as $K_{0}>0$, a separating equilibrium prevails, whereby governments for which $\psi_{1}=\psi_{1}\left(K_{0}, x\right)>0$ impose controls at the beginning of period one and all remaining governments allow free capital mobility. ${ }^{20}$ Figure 2 illustrates the equilibrium in this case, by plotting an illustrative curve $\psi_{1}$ (ignore the curve $\psi_{1}^{\mathrm{S}}$ and the point $x^{\mathrm{R}}$, for the moment). We have been unable to rule out the possibility of a nonmonotonic behavior of the curve $\psi_{1}$ (although we expect the curve to be decreasing in most plausible cases). In any case, the essence of Proposition 1 is that, even if the ranges of governments choosing $c_{1}=\mathbf{R}$ and $c_{1}=\mathrm{F}$ may not be connected, in equilibrium there will be enough probability mass attached to $c_{1}=\mathrm{R}$ at low values of $x$ to make capital controls in period one an unfavorable signal of $x$, and hence of future policies. With this caveat, henceforth we shall refer to low $x$ types as being more likely to impose controls in period one.

Next, observe that the profit-maximizing capital stock $K_{1}^{*}\left(\mu, K_{0}, \mathrm{~F}\right)$ in the high state $\mu_{1}=\mu$ conditional on free capital mobility lies strictly above its restricted-mobility counterpart, $K_{1}^{*}\left(\mu, K_{0}, \mathrm{R}\right)$ (the stocks are clearly both equal to zero in the low state $\mu_{1}=0$ ). This property clearly reflects the separating nature of the equilibrium: the observation of free capital mobility in 
period one triggers a discrete upward revision in investors' beliefs over government types, relative to their prior beliefs, and therefore an ex ante increase in expected returns to $K_{1}$. Symmetrically when capital controls are imposed in period one. The persistence of policies necessary for this result reflects the fact that low- $x$ governments are more likely than high- $x$ governments to impose controls in both periods.

The wedge $K_{1}^{*}\left(\mu, K_{0}, \mathrm{~F}\right)-K_{1}^{*}\left(\mu, K_{0}, \mathrm{R}\right)$ affects the response of capital flows to policies. Since $K_{1}^{*}\left(\mu, K_{0}, \mathrm{~F}\right)>K_{1}^{*}\left(\mu, K_{0}, \mathrm{R}\right)$ and $K_{1}{ }^{*}\left(0, K_{0}, \mathrm{~F}\right)=K_{1}^{*}\left(0, K_{0}, \mathrm{R}\right)=0$, for all $K_{0}$, then $\mathrm{E}_{1}\left[K_{1}^{*}\left(\mu_{1}, K_{0}, \mathrm{~F}\right)\right]=\pi K_{1}^{*}\left(\mu, K_{0}, \mathrm{~F}\right)>\pi K_{1}^{*}\left(\mu, K_{0}, \mathrm{R}\right)=\mathrm{E}_{1}\left[K_{1}^{*}\left(\mu_{1}, K_{0}, \mathrm{R}\right)\right]$, for all $K_{0}$. Hence, there is always a nontrivial range of initial states $K_{0}$, for which a policy of free capital mobility causes an expected inflow (i.e., $\left.\mathrm{E}_{1}\left[K_{1}^{*}\left(\mu_{1}, K_{0}, \mathrm{~F}\right)\right]>K_{0}\right)$, even though capital controls would lead to a desired outflow averaged across states $\left(K_{0}>\mathrm{E}_{1}\left[K_{1}^{*}\left(\mu_{1}, K_{0}, \mathrm{R}\right)\right]\right)$. Intuitively, governments with few outside resources impose controls as their decision is dominated by welfare under the worst scenario ( $\mu=0$, in our simple setup), while high $x$ governments are influenced more evenly by the whole distribution of $\mu_{t}$. Low $x$ governments impose controls because of the large costs associated with possible outflows, notwithstanding the potential benefits of free capital mobility.

The model also predicts the circumstances in which the choice of an open capital account will more likely cause a capital inflow. The likely outcome depends on the strength of the signal provided by that policy. The improvement in investors' beliefs over types, upon observation of $c_{1}=\mathrm{F}$, is sharper (and hence an inflow is more likely), the lower was the prior likelihood of an open capital account and the greater is the extent of policy persistence across periods. Clearly, for investors to attribute value to these news, they must attach sufficient 
importance to future policies: as (4) and (6) indicate, as the discount factor $\rho$ becomes small, the signaling effect of policies vanishes, investment converges to its one-shot outcome, and a removal of binding controls on outflows always causes an outflow.

C. The role of asymmetric information. To clarify the role of asymmetric information in our model, consider the case where investors are informed of $x$ at the beginning of period one. Clearly, there is no scope for signaling in this case: investors already know whether the host government will impose controls or not in period two at each $K_{1}$. Desired period-one capital would then be independent of the regime (i.e., $K_{1}^{*}\left(\mu_{1}, K_{0}, \mathrm{R}\right)=K_{1}^{*}\left(\mu_{1}, K_{0}, \mathrm{~F}\right)$ ), and a removal of binding controls on outflows would always cause an outflow. Thus, the possibility of an inflow following the removal of binding controls on outflows rests crucially, in our model, on the signaling role of policies.

Asymmetric information equilibria also exhibit "mimicking": some governments exploit informational asymmetries to pool with higher $x$ types and liberalize capital flows in period one, a policy they would not have adopted with symmetric information. To understand why this is true, consider the highest $x\left(x^{\mathrm{R}}\right.$, say, see Figure 2) just indifferent between controls and no controls in the asymmetric information case (thus, all types higher than $x^{\mathrm{R}}$ strictly prefer free capital mobility). With asymmetric information, $x^{\mathrm{R}}$ knows that if it imposes controls, investors will pool its type with types in a range with upper bound $x^{R}$ (and hence reduce their desired investment), when forming their best guess of the host government's type. Hence, aside from the benefits from trapping the given stock of capital onshore (which are identical with and without asymmetric information), with asymmetric information the type $x^{R}$ also faces a signaling cost when imposing controls in period one. No such cost arises with 
symmetric information: investors already know the host government to be of type $x^{\mathrm{R}}$. Hence, if $x^{\mathrm{R}}$ is indifferent between controls and no controls under asymmetric information, $x^{\mathrm{R}}$ must strictly prefer controls under symmetric information. Combining this observation with the fact that the symmetric information case features a simple split between governments imposing controls in period one and governments not imposing controls, (see Figure 2, where $\psi_{1}^{\mathrm{S}}\left(K_{0}, x\right)$ denotes the gains-from-controls function in the symmetric information case), then the types choosing free mobility with symmetric information form a strict subset of those choosing free mobility with asymmetric information. ${ }^{21}$ Thus, in our model, incomplete information about government attitudes toward capital mobility yields a bias toward liberal markets.

D. Extensions. The model of the previous sections is highly stylized, and several extensions could be considered. The main problem in pursuing some of these may be the loss of tractability: signaling models are notoriously hard to solve, and most of the signaling literature has resorted to simplifications such as quadratic loss functions, two-period or twotype models, etc., in order to obtain tractable solutions. In other cases, augmenting the model to endogenize some parameters may not justify the cost of blurring its message. This is likely to be the case, for instance, for more structural models of the motives and costs of capital controls to the extent that these yield reduced forms similar to those that we have simply assumed (whereby governments have an imperfectly known taste for domestic capital, but suffer a cost from imposing controls).

In some respects, our model is less restrictive than it may appear at first sight. The cost of controls $\xi$, for instance, could be allowed to vary across periods, to differ across 
governments, or to be incurred only when controls are binding (e.g., to rise as a function of the gap between onshore and offshore returns). When the cost $\xi$ is viewed as governmentspecific, the model's prediction that governments with minimal outside resources are more likely to impose controls on capital outflows must be viewed as a ceteris paribus prediction: governments less able (or willing) to tap outside revenues are more likely to impose controls than governments facing similar costs of imposing controls, but with easier access to outside revenues.

A positive cost $\xi$, however, is essential; otherwise the trade-off faced by governments in their policy decision disappears. ${ }^{22}$ Therefore, in situations where controls are seen as beneficial (for example, to insulate domestic markets from external shocks), other costs of disrupting capital mobility ought to be introduced in the model, for the government to face a meaningful decision problem.

Another simplifying assumption is that the capital stock invested onshore in period one remains intact until period two. When $K_{t}$ is viewed as physical capital, this assumption is equivalent to that of no capital depreciation; ${ }^{23}$ writing the capital controls' constraint as $K_{t} \geq K_{t-1}$, is also equivalent to assuming controls to be fully effective. Neither of these assumptions is very realistic. However, it is easy to extend the model by rewriting the controls' constraint as $K_{t} \geq(1-\delta) K_{t-1}$, and equations (2) to (4) with (1- $\left.\delta\right) K_{1}$ in place of the stock $K_{1}$ inherited from period one. All qualitative results remain unchanged, as long as $\delta<1$, that is, as long as capital does not depreciate fully from period to period, and controls are at least partially effective. In the degenerate case of $\delta=1$, investors need not be concerned with capital controls: their principal is fully lost (or fully transferrable offshore) in a single period 
anyway. In the more realistic case of $0<\delta<1$, instead, controls would be effective only in the short run. This is sufficient, however, to make investors afraid that a stock $(1-\delta) K_{1}$ may remain trapped onshore earning a low return, leading to a signaling equilibrium of the type studied above.

The payoffs to a more general model may be significant but tractability problems overwhelming, when extending the analysis to a multi-period model. It is clear from Section 3.B that our model has a recursive nature, and that government and investors would face a very similar problem in each period of a repeated game of duration $T$. However, whereas we could exploit in our solution for period one the semi-closed form solution available for period two, that strategy would only help for period $T-1$ in a multi-period model. Nevertheless, the two-period case has implications for some results one may anticipate for the multi-period case.

First, in our two-period model, while a true "liberalization" (in the sense of a removal of capital controls following their endogenous imposition) can occur in period two, a periodone liberalization would be conditional on inheriting a regime of restricted capital mobility from period zero. Clearly, a multi-period extension could produce richer patterns of liberalizations and re-impositions of controls, particularly when combined with a more general treatment of technology. In this respect, allowing for a continuous distribution for the technology shocks would needlessly complicate the model, but allowing for serially correlated shocks would have interesting implications. ${ }^{24}$ For instance, the stronger the correlation of the shocks, the more information on future tax revenues the government obtains from current shocks. A high correlation and a high value of $\mu$, would virtually eliminate the need for 
controls in response to a positive technology shock: there is no need to insure against bad states of nature if such states can be ruled out a priori; conversely in response to the arrival of bad news on future productivity.

We expect policies to respond to the same incentives in a multi-period model:

governments with low outside resources, who expect a narrow tax base in the future (because they expect a series of bad productivity shocks) would initially try to trap capital onshore by imposing controls. Subsequent arrival of good news on future tax revenues, in the form of a large, highly correlated technology shock, would make these governments liberalize capital flows.

Finally, a multi-period model may make the impact of reputational effects on capital flows even more dramatic. As discussed above, there are governments who would impose restrictions if their type were known, but allow free capital mobility under asymmetric information in order to be perceived as more likely to adopt liberal policies in the future. The intuition from our two-period and other signaling models suggest that this reputational effects could be long-lived.

\section{Concluding Remarks}

We have presented a model in which governments can use policies affecting capital mobility to signal a favorable future fiscal situation. In our model, governments with the most to lose from a capital outflow are more likely to fall prey to the temptation of trapping capital onshore; governments with less to gain from a capital inflow are more likely to withstand such temptation and to allow free capital mobility. Investors recognize these 
incentives and the persistence of policies affecting capital flows: governments liberalizing capital flows today are more likely not to impose controls tomorrow, and vice versa.

Ironically (but intuitively), governments with less need for a large tax base are more likely to experience a capital inflow. These predictions are consistent with the observed experience of a number of countries that have liberalized their capital accounts. Our model suggests to view those policy shifts as enhancing the credibility of those countries as hosts for foreign investment. A desired inflow upon liberalization, the model suggests, was fully consistent with a desired outflow conditional on a repressed capital account.

While capital controls are motivated in our model by their role in broadening the domestic tax base, the model's insight should extend to related problems. The main alternative would be to explore the role of capital controls to defend an exchange rate target. We expect this motive to lead to similar predictions on the response of investment to capital controls policies. Investors fear being trapped onshore earning a low rate of return and would welcome with an inflow news suggesting lower likelihood of controls in the future.

Governments with less to lose from a balance of payment crisis would try to signal their commitment to free capital mobility by exposing themselves to greater chances of a crisis. In so doing, they would differentiate themselves from those governments that cannot afford to take chances, thus validating the signaling content of the liberalization. 


\section{Table 1. Time structure of the model}

$t=0$ : - Inherited stock of capital: $K_{0}$.

$t=1:-x$ is revealed to the government.

- Government chooses $c_{1} \in\{F, R\}$.

- $\mu_{1} \in\{0, \mu\}$ is realized and revealed.

- Public chooses $K_{!}$(with $K_{1} \geq K_{0}$ if $c_{1}=\mathrm{R}$ ).

- Production takes place, profits are collected.

$t=2:-x$ is revealed to the public.

- Government chooses $c_{2} \in\{F, R\}$.

- $\mu_{2} \in\{0, \mu\}$ is realized and revealed.

- Public chooses $K_{2}$ (with $K_{2} \geq K_{1}$ if $c_{2}=\mathrm{R}$ ).

- Production takes place, profits are collected, taxes are paid and transformed into public goods (together with $x$ ).

\section{Appendix}

Proof of Proposition 1: The proof is by contradiction. It verifies that under the converse assumption $\psi_{1}\left(K_{0}, x\right)$ falls with $x$ for all $K_{0}$ and $x$. Write $K_{1}^{\mathrm{F}} \equiv K_{1}^{*}\left(\mu, K_{0}, \mathrm{~F}\right)$, $K_{1}^{\mathrm{R}} \equiv K_{1}^{*}\left(\mu, K_{0}, \mathrm{R}\right)$, and $K_{2}^{*} \equiv K_{2}^{*}\left(\mu_{2}\right)$. Let $x_{2}^{\mathrm{T}}\left(K_{1}\right)$ be the unique type $x$ indifferent between controls and no controls at the beginning of period two, given $K_{1}$, and recall that $\pi$ and $1-\pi$ are the probabilities that $\mu_{t}=\mu$ and $\mu_{t}=0$, respectively, which may depend on $\left\{\mu_{t-1}, \mu_{t-2}, \ldots\right\}$. We have three cases defined by the relationship between $K_{0}$ and $\mu$ : 
1. low $K_{0}$ (or high $\mu$ ): $K_{0} \leq K_{1}^{\mathrm{F}} \leq K_{1}^{\mathrm{R}}$.

a. $x \leq x_{2}{ }^{\mathrm{T}}\left(K_{0}\right)$ (this is the range of $x$ that would impose controls in period two at $\left.K_{0}\right)$ :

(A1) $\psi_{1}\left(K_{0}, x\right)=\pi \rho^{2} \mathrm{E}_{1}\left[W\left(\tau \cdot \max \left\{K_{1}^{\mathrm{R}}, K_{2}^{*}\right\}+x\right)-W\left(\tau \cdot \max \left\{K_{1}^{\mathrm{F}}, K_{2}^{*}\right\}+x\right)-\frac{\xi}{\rho}\right]$

$$
+(1-\pi) \rho^{2} \mathrm{E}_{1}\left[W\left(\tau \cdot \max \left\{K_{0}, K_{2}^{*}\right\}+x\right)-W\left(\tau \cdot K_{2}^{*}+x\right)-\frac{\rho}{\rho}-\xi\right]
$$

with expectations taken over $\mu_{2}$, conditional on $\mu_{1}$.

b. $x_{2}^{\mathrm{T}}\left(K_{0}\right) \leq x \leq x_{2}^{\mathrm{T}}\left(K_{1}^{\mathrm{F}}\right)$ :

(A2) $\psi_{1}\left(K_{0}, x\right)=\pi \rho^{2} \mathrm{E}_{1}\left[W\left(\tau \cdot \max \left\{K_{1}^{\mathrm{R}}, K_{2}^{*}\right\}+x\right)-W\left(\tau \cdot \max \left\{K_{1}^{\mathrm{F}}, K_{2}^{*}\right\}+x\right)-\frac{\xi}{\rho}\right]$

$$
+(1-\pi) \rho^{2} \mathrm{E}_{1}\left[W\left(\tau \cdot K_{2}^{*}+x\right)-W\left(\tau \cdot K_{2}^{*}+x\right)-\frac{\xi}{\rho}\right]
$$

c. $x_{2}^{\mathrm{T}}\left(K_{1}^{\mathrm{F}}\right) \leq x \leq x_{2}{ }^{\mathrm{T}}\left(K_{1}^{\mathrm{R}}\right)$ :

(A3) $\psi_{1}\left(K_{0}, x\right)=\pi \rho^{2} \mathrm{E}_{1}\left[W\left(\tau \cdot \max \left\{K_{1}^{\mathrm{R}}, K_{2}^{*}\right\}+x\right)-W\left(\tau \cdot K_{2}^{*}+x\right)-\frac{\xi}{\rho}-\xi\right]$

$$
+(1-\pi) \rho^{2} \mathrm{E}_{1}\left[W\left(\tau \cdot K_{2}^{*}+x\right)-W\left(\tau \cdot K_{2}^{*}+x\right)-\frac{\xi}{\rho}\right]
$$

d. $x_{2}{ }^{\mathrm{T}}\left(K_{1}^{\mathrm{R}}\right) \leq x$ :

(A4) $\psi_{1}\left(K_{0}, x\right)=\pi \rho^{2} \mathrm{E}_{1}\left[W\left(\tau \cdot K_{2}^{*}+x\right)-W\left(\tau \cdot K_{2}^{*}+x\right)-\frac{\xi}{\rho}\right]$

$$
+(1-\pi) \rho^{2} \mathrm{E}_{1}\left[W\left(\tau \cdot K_{2}^{*}+x\right)-W\left(\tau \cdot K_{2}^{*}+x\right)-\frac{\xi}{\rho}\right]
$$

2. intermediate $K_{0}$ (or intermediate $\mu$ ): $K_{1}^{\mathrm{F}} \leq K_{0} \leq K_{1}^{\mathrm{R}}$.

a. $x \leq x_{2}{ }^{\mathrm{T}}\left(K_{1}^{\mathrm{F}}\right):$ same as (A1).

b. $x_{2}^{\mathrm{T}}\left(K_{1}^{\mathrm{F}}\right) \leq x \leq x_{2}^{\mathrm{T}}\left(K_{0}\right)$ :

(A5) $\psi_{1}\left(K_{0}, x\right)=\pi \rho^{2} \mathrm{E}_{1}\left[W\left(\tau \cdot \max \left\{K_{1}^{\mathrm{R}}, K_{2}^{*}\right\}+x\right)-W\left(\tau \cdot K_{2}^{*}+x\right)-\frac{\xi}{\rho}-\xi\right]$

$$
+(1-\pi) \rho^{2} \mathrm{E}\left[W\left(\tau \cdot \max \left\{K_{0}, K_{2}^{*}\right\}+x\right)-W\left(\tau \cdot K_{2}^{*}+x\right)-\frac{\xi}{\rho}-\xi\right]
$$

c. $x_{2}^{\mathrm{T}}\left(K_{0}\right) \leq x \leq x_{2}^{\mathrm{T}}\left(K_{1}^{\mathrm{R}}\right)$ : same as (A3).

d. $x_{2}^{\mathrm{T}}\left(K_{1}^{\mathrm{R}}\right) \leq x$ : same as (A4). 
3. high $K_{0}$ (or low $\mu$ ): $K_{1}^{\mathrm{F}} \leq K_{1}^{\mathrm{R}}<K_{0}$.

a. $x \leq x_{2}^{\mathrm{T}}\left(K_{1}^{\mathrm{F}}\right)$ : same as (A1).

b. $x_{2}^{\mathrm{T}}\left(K_{1}^{\mathrm{F}}\right) \leq x \leq x_{2}^{\mathrm{T}}\left(K_{1}^{\mathrm{R}}\right)$ : same as (A5).

c. $x_{2}^{\mathrm{T}}\left(K_{1}^{\mathrm{R}}\right) \leq x \leq x_{2}^{\mathrm{T}}\left(K_{0}\right)$ :

(A6) $\psi_{1}\left(K_{0}, x\right)=\pi \rho^{2} \mathrm{E}_{1}\left[W\left(\tau \cdot \max \left\{K_{0}, K_{2}^{*}\right\}+x\right)-W\left(\tau \cdot K_{2}{ }^{*}+x\right)-\frac{\xi}{\rho}-\xi\right]$ $+(1-\pi) \rho^{2} \mathrm{E}_{1}\left[W\left(\tau \cdot \max \left\{K_{0}, K_{2}^{*}\right\}+x\right)-W\left(\tau \cdot K_{2}^{*}+x\right)-\frac{\xi}{\rho}-\xi\right]$

d. $x_{2}{ }^{\mathrm{T}}\left(K_{0}\right) \leq x$ : same as $(\mathrm{A} 4)$.

Now, by (4) and (5), if $\gamma^{\mathrm{F}} \geq \gamma^{\mathrm{R}}$, then $K_{1}{ }^{\mathrm{F}} \leq K_{1}^{\mathrm{R}}$. Then $\mathrm{E}_{1}\left[W\left(\cdot \mid c_{1}=\mathrm{R}\right)\right] \geq$ $\mathrm{E}_{1}\left[W\left(. \mid c_{1}=\mathrm{F}\right)\right]$ for all ranges of $x$ and for all cases 1 to 3 , with strict inequality over ranges with positive probability. Furthermore, the difference between the two sides of the inequality is decreasing in $x$, due to the concavity of $W($.$) , which implies that sufficiently low x$ 's impose controls in period one, while higher $x$ 's do not. Since this is also true in period one, then $\gamma^{\mathrm{F}}<\gamma^{\mathrm{R}}$, a contradiction. 
Figure 1

Capital account and foreign exchange reserves: Italy, Spain, New Zealand and Uruguay
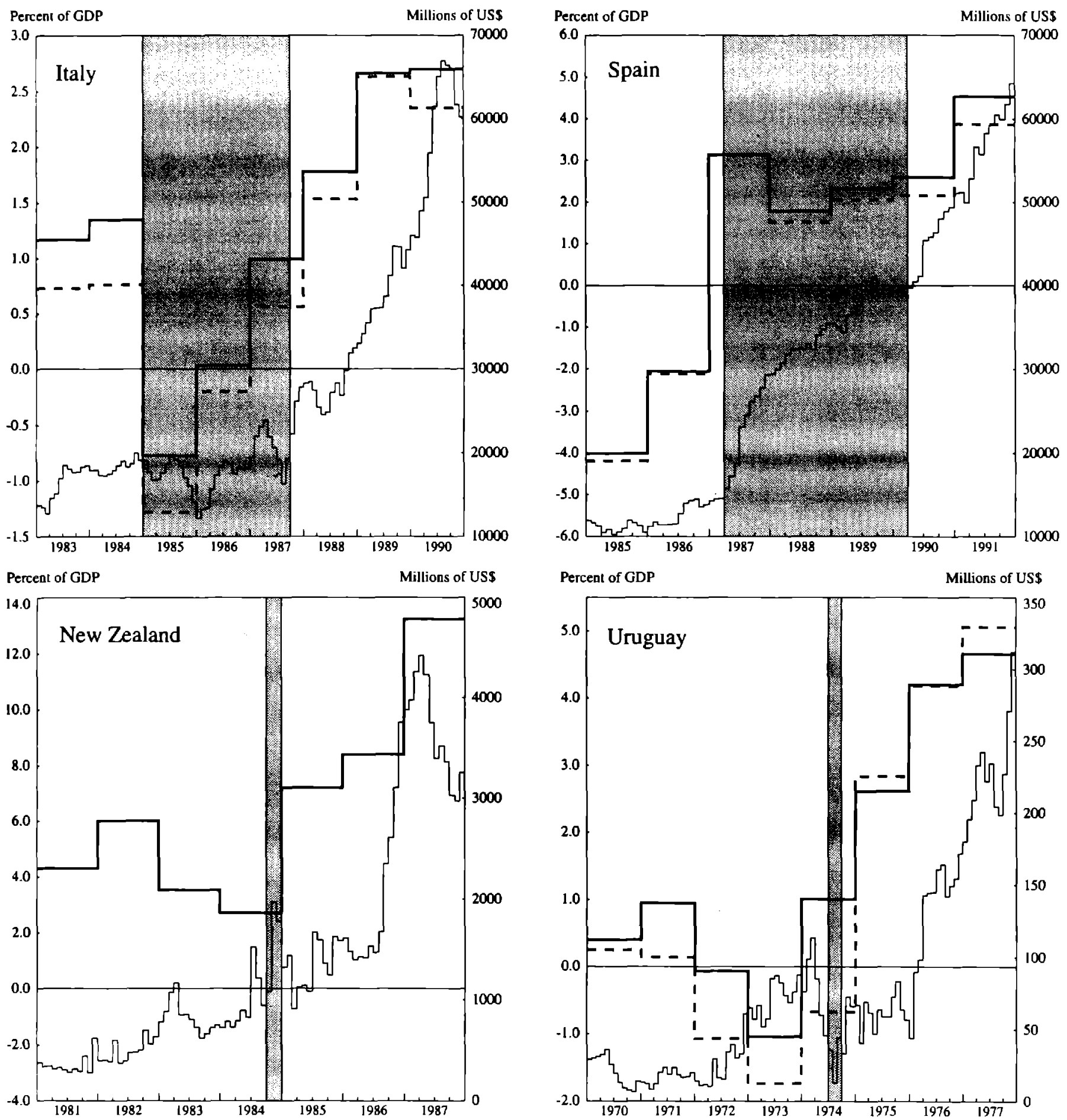

- Capital account (left axis; net of FDI for Spain)

- - Capital account minus net loans (net official loans for Spain) to the public sector (left axis)

- Foreign exchange reserves (right axis)

Shaded areas indicate periods of main liberalization measures. Capital flows include errors and omissions.

Sources, various issues of: IMF, Intemational Financial Statistics; Banco Central del Uruguay, Indicadores de la Actividad Economico-Financiera; Banca d'Italia, Rapporto Annuale; Banco de Espana, Boletin Estadistico; The World Bank, World Debt Tables; and data provided by the New Zealand Department of Finance. 
Figure 2

Equilibrium Capital Controls Policies in Period One

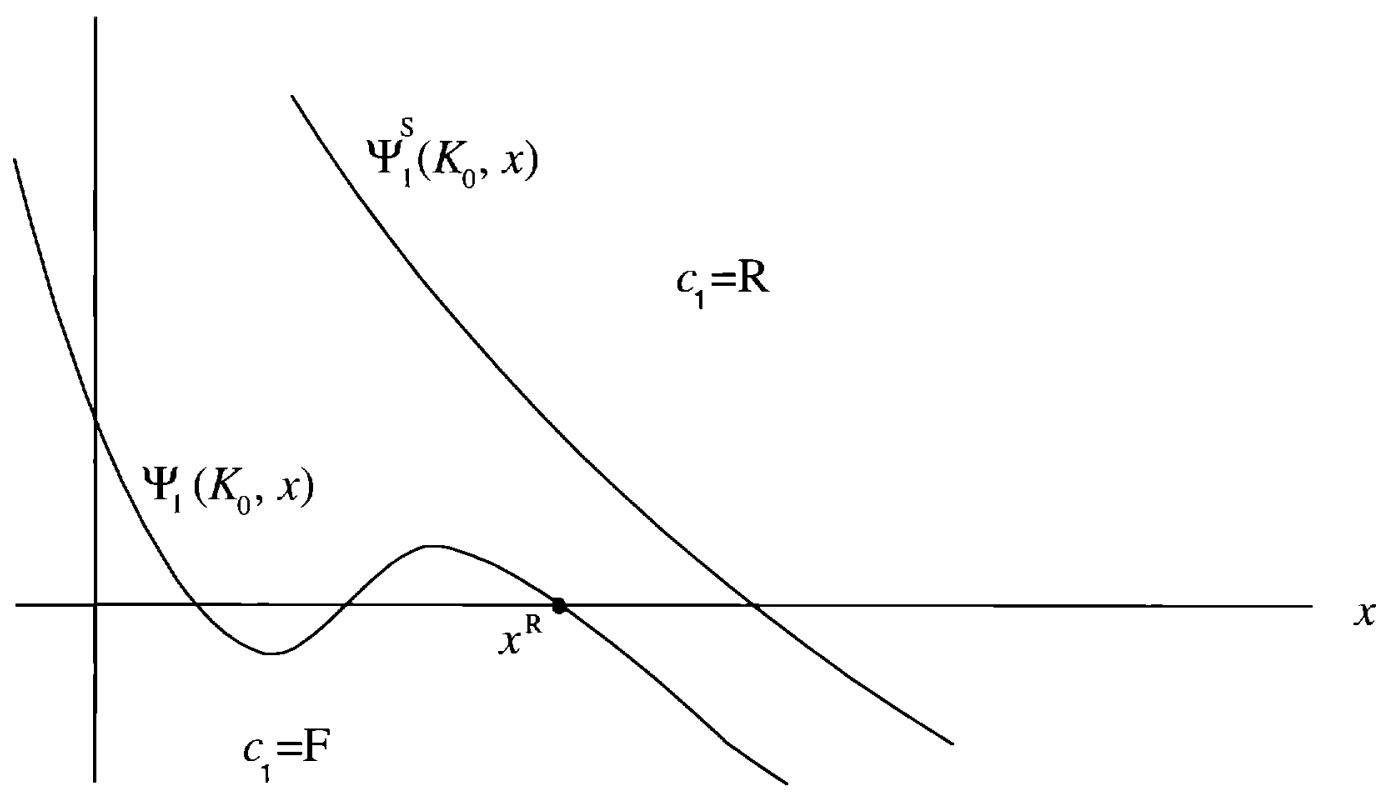




\section{Endnotes}

${ }^{1}$ See, for instance, Obstfeld (1984) and Bacchetta (1992).

${ }^{2}$ Giavazzi and Spaventa (1990). Williamson (1991), Mathieson and Rojas-Suarez (1993), and Labán and Larraín (1993), among others, review a number of such episodes.

${ }^{3}$ As documented in Figure 1, (net) capital flows minus (net) loans to the public sector surged beginning in 1986-87. (Although Italy does not classify capital flows by characteristics of foreign investors, flows from official agencies and other governments should be almost entirely included among foreign loans to the public sector.)

${ }^{4}$ Although the hands-off approach following the liberalization limits data availability, net flows to the private sector were noted as growing faster and to a higher level, than those to the public sector (see New Zealand, Reserve Bank, January 1986 and July 1986 Bulletins and OECD, 1987). Even flows to the public sector originated wholly at market terms, mainly through sale of Government Stocks and Kiwi Bonds.

${ }^{5}$ See Banda and Santo (1983), de Melo (1985), and Pérez-Campanero and Leone (1991) for reviews of the Uruguay episode.

${ }^{6}$ Liberalization of inflows affected mainly FDI in selected sectors; hence, to avoid overstating our case, since the FDI growth may reflect the lifting of these restrictions, Figure 1 reports data net of FDI.

${ }^{7}$ Alesina, Grilli, and Milesi-Ferretti (1994) list four main motives for capital controls (i. limit volatile capital flows; ii. maintain the domestic tax base; iii. retain domestic savings, and iv. sustain structural reform) and study their determinants across countries and over time. They identify in governments' attempt to collect revenue from financial repression the main 
motive for controls. See also Giovannini and de Melo (1993) and Aizenman and Guidotti (1994).

${ }^{8}$ Alesina and Tabellini (1989), for instance, include the loss of capitalists' electoral support to governments that impose controls among the political costs of capital controls.

${ }^{9}$ Allowing for consumers' risk aversion, for instance, Lucas (1987) and Mendoza (1991) estimate a loss of utility from inability to smooth consumption through international diversification in the order of .10 percent. Backus, Keohe, and Kydland (1990) report similar results.

${ }^{10}$ See Bartolini and Drazen (1996) for a model (with a different information structure) where government policies respond to changes in external conditions.

${ }^{11}$ As suggested by a referee, our model could also be interpreted as a model of international investment in physical capital. where the multi-period horizon reflects the gestation lag necessary for direct investment to become fully productive.

${ }^{12}$ The issues that arise when the government is unable to pre-commit to a fixed tax rate were studied by Fischer (1980). We simplify the model by assuming commitment to a fixed tax rate at time zero.

${ }^{13}$ Exponential utility would satisfy all these regularity conditions.

${ }^{14}$ See for instance, Rogoff (1987), where the cost of breaking a no-inflation commitment is modeled as independent of the inflation rate itself, and Barro (1986), where a government's cost is zero for zero inflation and prohibitive for positive inflation.

${ }^{15}$ Little is lost with this assumption, since governments' utility is already a function of $K_{1}$ and $x$, and could be redefined net of other costs that depend on these variables (e.g., as a function 
of the gap between offshore and onshore returns). Explicit role for residents' welfare could also be included, by defining government's welfare as utility from public consumption plus consumers' utility from domestic output, produced with onshore capital and a fixed stock of labor.

${ }^{16}$ We focus on controls on capital outflows. As it will become clear later, in this model there are no incentives to restrict inflows.

${ }^{17}$ To see this, note that $\beta K_{1}^{\beta-1}$ falls with $K_{1}$ from infinity to zero; that $\gamma^{c_{1}}$ is increasing in $K_{1}$, given $K_{0}$, and for both $c_{1}=\mathrm{R}$ and $c_{1}=\mathrm{F}$ (since $\psi_{2}\left(K_{1}, x\right)$ rises with $K_{1}$--see Section 3.A); and that the term in square brackets is positive and continuous (including where (1) holds identically with $\mu_{2}=\mu$ and $K_{2}=K_{1}$, and $I^{\prime}$ switches from zero to one).

${ }^{18}$ In particular, it does not seem possible to rule out, in general, multiple intersections between the function $\psi_{1}\left(K_{0}, x\right)$ (as this goes from $+\infty$ for $x \rightarrow-\infty$, to $-\rho \xi$ for $x \rightarrow+\infty$ ) and the horizontal axis.

${ }^{19}$ See also Gordon and Levinsohn (1989) and Giovannini and de Melo (1993), who argue that financial repression in developing countries dominates other forms of taxation that are too costly to organize and administer. Value-added or consumption taxes, for instance, require sophisticated methods of assessment. border controls, and other measures that may simply be beyond the reach of many poor countries.

${ }^{20}$ When $K_{0}=0$, all governments (other than, trivially, the type $x=-\infty$ ) allow free mobility, a pooling equilibrium prevails in period one, $K_{l}^{*}\left(\mu_{1}, K_{0}, \mathrm{~F}\right)=K_{l}^{*}\left(\mu_{1}, K_{0}, \mathrm{R}\right)$, and signaling plays no role in the ensuing capital flow. We focus here on the case of $K_{0}>0$. 
${ }^{21}$ The argument showing that $\psi_{1}^{5}$ is decreasing in $x$ is similar to that for Proposition 1: with symmetric information, there is no role for signaling, and $K_{1}{ }^{*}\left(\mu_{1}, K_{0}, \mathrm{R}\right)=K_{1}^{*}\left(\mu_{1}, K_{0}, \mathrm{~F}\right)$. Then, controls can only increase $K_{1}$ and $K_{2}$; hence, low $x$ types, who benefit more from a larger tax base, are more inclined to impose controls in all periods.

${ }^{22}$ All governments would impose controls in period two and, lacking signaling or direct cost of doing otherwise, also in period one.

${ }^{23}$ When $K_{r}$ is regarded as a financial claim on returns from physical capital, the same assumption is equivalent to that of no default risk.

${ }^{24}$ In our two-period model this extension would only require to specify the transition probabilities for the technology shocks as conditional on previous states, e.g., $\pi^{\mu} \equiv \operatorname{Pr}\left(\mu_{t}=\mu \mid \mu_{t-1}=\mu\right), \pi^{0} \equiv \operatorname{Pr}\left(\mu_{,}=\mu \mid \mu_{t-1}=0\right)$, with $1-\pi^{\mu}$ and $1-\pi^{0}$ defined accordingly; then, $\pi^{\mu}>1 / 2>\pi^{0}$ yields positively correlated shocks. All results would remain qualitatively unchanged. 


\section{References}

Aizenman, Joshua, and Guidotti, Pablo. "Capital Controls, Collection Costs and Domestic Public Debt." Journal of International Money and Finance, 1994, 13, pp. 41-54.

Alesina, Alberto, and Tabellini, Guido. "External Debt, Capital Flight and Political Risk." Journal of International Economics, 1989, 27, pp. 199-220.

Alesina, Alberto, Grilli, Vittorio, and Milesi-Ferretti, Gian Maria. "The Political Economy of Capital Controls," in Leonardo Leiderman and Assaf Razin, eds., Capital Mobility: The

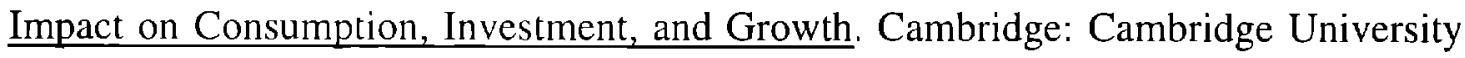
Press, 1994.

Bacchetta, Philippe. "Liberalization of Capital Movements and of the Domestic Financial System." Economica, 1992, 59, pp. 465-474.

Backus, David, Keohe, Patrick, and Kydland, Finn. "International Real Business Cycles." Federal Reserve Bank of Minneapolis, Working Paper No. 426R, 1990.

Banda, A., and Santo, M. "Una Aproximacion Empirica al Estudio de los Sustitutos del Dinero en Uruguay." Monetaria, 1983, pp. 301-314.

Barro, Robert. "Reputation in a Model of Monetary Policy with Incomplete Information." Journal of Monetary Economics, $1986, \underline{17}$, pp. 3-20.

Bartolini, Leonardo, and Bodnar, Gordon. "An Analysis of the Process of Capital Liberalization in Italy." IMF WP/92/27, 1992.

Bartolini, Leonardo, and Drazen, Allan. "When Liberalization Reflects External Shocks, What Do We Learn?" University of Maryland, mimeo.

de Melo, Jaime. "Financial Reforms, Stabilization, and Growth Under High Capital Mobility: Uruguay 1974-83." World Bank, DRD Discussion Paper No. 138, 1985. 
Dooley, Michael, and Isard, Peter. "Capital Controls, Political Risk, and Deviations from Interest-Rate Parity." Journal of Political Economy, 1980, $\underline{88}$, pp. 370-384.

Fischer, Stanley. "Dynamic Inconsistency, Cooperation, and the Benevolent Dissembling Government." Journal of Economic Dynamics and Control, 1980, 2, pp. 93-107.

Frenkel, Jacob, and Razin, Assaf. Fiscal Policies and the World Economy. Cambridge: MIT Press, 1987.

Fudenberg, Drew, and Tirole, Jean. "Perfect Bayesian Equilibrium and Sequential Equilibrium." Journal of Economic Theory, 1991, 53, pp. 236-60.

Giavazzi, Francesco, and Spaventa, Luigi. "The 'New' EMS." CEPR Discussion Paper No. $369,1990$.

Giavazzi, Francesco, and Giovannini, Alberto. Limiting Exchange Rate Flexibility: The European Monetary System. Cambridge: MIT Press, 1989.

Giovannini, Alberto, and de Melo, Martha. "Government Revenue from Financial Repression." American Economic Review, 1993, $\underline{83}$, pp. 953-963.

Gordon, Roger, and Levinsohn, James. "The Linkage Between Domestic Taxes and Border Taxes." University of Michigan, mimeo, 1989.

International Monetary Fund. Exchange Arrangements and Exchange Restrictions. Washington: IMF, 1995.

Labán, Raúl, and Larraín, Felipe. "Can a Liberalization of Capital Outflows Increase Net Capital Inflows?" Universidad Catolica de Chile, Working Paper No. 155, 1993. Lucas, Robert. Models of Business Cycles. Oxford: Basil Blackwell, 1987. Mathieson, Donald, and Rojas-Suarez, Liliana. Liberalization of the Current Account. Washington: IMF, Occasional Paper No. 103, 1993. 